\title{
Contribuição de Melhoria e Taxa de Iluminação Pública
}

\author{
Ruy Barbosa Nogueira \\ Catedrático de Direito Tributário e Professor \\ de Direito Tributário Comparado - USP. \\ Presidente do IBDT.
}

\begin{abstract}
Sumário: $A$ execuçāo da obra de iluminação pública e seu custeio pela Contribuição de Melhoria - A manutenção e fornecimento do serviço de iluminação das mas e logradouros para - povo, como despesa geral a ser custeada pelos impostos e jamais por meio de taxas - Características constitucionais, legais e doutrinárias das taxas - Soluções jurisprudenciais $A$ lógica e harmonia entre os vários tributos na organização destes em SISTEMA - As comprovações no campo do Direito Comparado.
\end{abstract}

Na 352. a reunião da Mesa Semanal de Debates do InstiTUTO BRASILEIRo DE DIREITO TRIBUTÁRIO, entidade complementar à USP, realizada na Faculdade de Direito do Largo São Francisco, foi levantada a questão de saber-se se as Prefeituras Municipais podem cobrar dos munícipes Taxa de iluminação das ruas e logradouros públicos ou, como diz o Anteprojeto de Código Tributário do Município de São Paulo, taxa "de manutenção da rede elétrica", e, ainda, se por ocasião da realização da obra de iluminação pública pode seu custo ser ressarcido por meio da Contribuição de Melhoria.

Designado relator, apresentamos o seguinte trabalho, que foi unanimemente aprovado:

CONTRIBUIÇÃo DE MELHORIA: realização de obra pública

I - De acordo com o art. 18 II da Constituição Federal, explicitados pelos arts. 81 e 82 do CTN e na conformidade da jurisprudência já sedimentada por reiterados acórdãos do Supremo Tribunal Federal, para se indenizar do custo da obra pública de iluminação das vias e logradouros, o Município pode instituir, lançar e cobrar dos proprietários de imóveis valorizados por tal obra, Contribuição de Melhoria, que terá como limite total a despesa realizada e como limite indivi- 
dual o acréscimo de valor que da obra resultar para cada imóvel beneficiado. (Vide no magnífico trabalho do jurista LUIZ JosÉ DE MESQUiTA, publicado no Suplemento Tributário LTr n. 44/81 e também na revista Fisco e Contribuinte n. 5, maio de 1981, sob o título Taxa e Contribuição de Melhoria, especialmente os itens: "13. A jurisprudência atual do STF. 14. Sentenças luminosas. 15. Conclusões".)

Observe-se bem que nesta primeira parte deste estudo estamos nos referindo à realização da obra de iluminação pública, da qual resulte valorização para os imóveis beneficiados e não ao serviço ou manutenção dessa iluminação. A valorização está, precisamente na consideração de que essa obra, uma vez concluída, proporcionará a iluminação pública, isto é, deverá necessária e suficientemente ser mantida em funcionamento para o uso geral ou comunitário.

II - Pois bem. O substrato, fato ou relação fática que distingue a possibilidade da cobrança da Contribuição de Melhoria da cobrança da Taxa, está precisamente em que, para a primeira, o governo realize obra pública de que resulte valorização dos imóveis dos respectivos contribuintes, enquanto que, para legitimar a cobrança de taxa de serviço é preciso que efetivamente preste ou ponha à disposição do respectivo contribuinte um serviço público específico para o utene e por isso mesmo, quando esse serviço atenda a um grupo ou coletividade, seja de natureza divisível entre os usuários e compulsório.

A distinção entre obra e serviço, para esses efeitos, foi feita com clareza e precisão pelo Mestre HELY LoPES MEIRELles, em seu já clássico livro, Direito Municipal Brasileiro, nestes termos:

"O que caracteriza a obra e a distingue do serviço é a predominância do material sobre o trabalho (mão-de-obra), pois em toda obra entram serviços, mas estes são superados pelos materiais empregados na estrutura em formação ou modificação. Essa distinção entre obra e serviço é feita pela Administração Pública, tanto para a determinação dos tributos, que podem incidir sobre aquela e este, como para saber-se qual a modalidade de licitação a que fica sujeito o contrato da obra ou do serviço" (Editora Rev. Tribunais, S. Paulo, 1977, 3. ed., pág. 148).

III - Assim, respondendo à dúvida sobre a possibilidade de o Município instituir, lançar e cobrar a Contribuição de Melhoria dos beneficiários da valorização imobiliária, para se 
indenizar do custo de cada obra de iluminação pública que realize, respondemos Sim: pode instituir, lançar e exigir tributo indenizatório por meio da espécie ou categoria denominada Contribuição de Melhoria, nos termos dos citados dispositivos da Constituição Federal e do CTN.

Para mais amplos esclarecimentos aos srs. legisladores e prefeitos municipais, em relação às possibilidades da correta instituição, lançamento e cobrança deste importante tributo, recomendamos a magnífica obra de JoÃo BAPTISTA MoREIRA, Contribuição de Melhoria que constitui o vol. VIII do Tratado de Direito Tributário Brasileiro, idealizado por ALIOMAR BALEEIRO, edição Forense, Rio, 1981.

\section{Taxa por prestação de serviço público}

IV - De acordo com os textos da Constituição Federal (art. 18, I e $\S 2 .^{\circ}$ ) ; do CTN (arts. 77 e 78 ), da atual jurisprudência do Supremo Tribunal Federal e a nosso ver da melhor e quase unânime doutrina pátria, como a dos maiores tributaristas de países cujos sistemas tributários, em matéria de taxas, são afins com o do Sistema Tributário Nacional, não pode o Município instituir TAXA para se indenizar do custo da manutenção do serviço de iluminação de vias e logradouros públicos, porque esse serviço público é de uso comum ou "ut universi". Não é serviço específico, não é serviço especial nem divisível "ut singuli". Tal serviço é parte integrante dos chamados serviços públicos gerais que o Estado proporciona ou põe à disposição do povo e devem ser custeados pelos impostos pagos pelos contribuintes de acordo com suas respectivas capacidades contributivas, entre os quais se destacam os proprietários de imóveis, que aliás são também os únicos possíveis sujeitos passivos da Contribuição de Melhoria, sendo certo que esta, no caso da obra de iluminação pública, implica em a iluminação ser efetivamente mantida.

$\mathrm{V}$ - Também parece justo observar que, além de os proprietários serem os únicos possíveis sujeitos passivos da Contribuição de Melhoria, já são também eles os sujeitos passivos do Imposto municipal sobre a Propriedade Predial e Territorial Urbana (CTN art. 32). São, de modo geral os que, revelando maior capacidade contributiva, mais se sujeitam aos impostos destinados à cobertura das despesas gerais. Não há dúvida que a manutenção da iluminação das ruas e logradouros públicos é que valoriza seus imóveis, mas como já dissemos, é precisamente em razão dessa valorização que são os únicos possíveis sujeitos passivos da Contribuição de Melhoria. É certo 
que na posição de membros da coletividade, terão o direito ao uso das vias e logradouros iluminados, mas esse será sempre o uso comum, assegurado igualmente a eles como aos demais utentes, todos, indistintamente, como integrantes da coletividade. Este uso é "ut universi" e não "ut singuli", como é óbvio e estatui o Código Civil.

VI - Com efeito. Ao classificar ontologicamente os bens públicos e teleologicamente fazer sua qualificação jurídico-normativa, dispõe o Código Civil Brasileiro:

Art. 66 - Os bens públicos são:

I - Os de uso comum do povo, tais como os mares, rios, estradas, ruas e praças.

II - Os de uso especial, tais como edifícios ...

III - Os dominicais, isto é, os que constituem o patrimônio da União, dos Estados ou dos Municípios.

Como se vê, as ruas e praças, dentro da própria tipologia legal, são modelos de bens de uso comum do povo. Ao comentá-lo, Clóvis Bevilaqua diz que estes do item I "são os que pertencem a todos (res communes omnium). 0 proprietário desses bens é a coletividade, o povo. A administração pública estão confiadas a guarda e gestão. Podem utilizar-se deles todas as pessoas, respeitadas as leis e os regulamentos".

Como não cabe ao direito civil dispor sobre finanças públicas, teve o sábio legislador de nosso monumental Código Civil o cuidado de esclarecer, em relação à utilização:

Art. 68 - $\mathrm{O}$ uso comum dos bens públicos pode ser gratuito, ou retribuído, conforme as leis da União, dos Estados, ou dos Municípios, a cuja administração pertencerem.

VII - Ora, a Reforma Tributária incluiu dentro da própria Constituição Federal um capítulo especial estruturando o "Sistema Tributário" (Tit I, Cap. V), e a legislação de ordem complementar, de cogência nacional, isto é, tanto à União, como aos Estados-membros e aos Municípios, dispondo sobre as competências, sobre todos os tributos e os harmonizando entre si, permitiu, como vimos, a instituição da Contribuição de Melhoria para os citados casos de obra pública. Entretanto, por meio de disposições expressas e conceituais da taxa não permite que, pelo uso comum da iluminação das ruas e praças possa ser cobrada a espécie denominada TAXA, se não vejamos. 
VIII - Entre as competências que a Constituição Federal outorga ao Município, encontram-se, com as respectivas limitações conceituais, ou definidoras das taxas, as seguintes normas:

Art. 18 - Além dos impostos previstos nesta Constituição .. compete aos Municípios instituir:

I - taxas, pela utilização efetiva ou potencial de serviços públicos específicos e divisiveis, sição. prestados ao contribuinte ou postos à sua dispo-

IX - Por sua vez, o CTN, com o caráter de legislação complementar da Constituição e as funções que lhe atribui o $\S 10^{\circ}$ do art. 18 desta, entre as quais as de estabelecer normas gerais e regular as limitações constitucionais do poder de tributar, dispõe que:

Art. 77 - As taxas cobradas pelos Municípios, no âmbito de suas respectivas atribuições, têm como fato gerador a utilização, efetiva ou potencial, de serviço público específico e divisivel, prestado ao contribuinte ou posto à sua disposição.

Art. 79 - Os serviços públicos a que se refere o art. 77 consideram-se:

I - utilizados pelo contribuinte:

a) efetivamente, quando por ele usufruidos a qualquer título;

b) potencialmente, quando, sendo de utilização compulsória sejam postos a sua disposição mediante atividade administrativa em efetivo funcionamento;

II - específicos, quando possam ser destacados em unidades autônomas de intervenção de utilidade ou de necessidades públicas;

III - divisíveis, quando suscetíveis de utilização, separadamente, por parte de cada um dos seus usuários.

$\mathrm{E}$ evidente, pois, que tendo todos, indistinta ou indivisivelmente como "povo" o direito ao uso comum das ruas e praças, sejam iluminadas ou não, a manutenção do serviço público de iluminação não é um serviço específico nem tão pouco divisível, destacável em unidades autônomas de sua utilidade ou utilização. Se é, por sua natureza (ontologia) comum (iluminação 
pública ou do povo) e por sua finalidade (teologia) a todos, indistintamente (iluminação pública ou para o povo), de acordo com a própria qualificação jurídico-normativa constitucional e da legislação nacional ou complementar sobre o "factum", isto é, do "serviço público" suscetível de ser pressuposto fático da taxa (relação fática, "sachverhalt"), vê-se que esta é insuscetível de ser "fato gerador" de taxa porque não é um serviço ou prestação de serviço específico, nem destacável em unidades autônomas de utilidade, nem prestado individualmente ao contribuinte (mas a todos), nem individualmente por ele usufruído (mas indistintamente por todos). Em resumo é serviço de uso comum (ut universi).

$\mathrm{X}$ - Vê-se, pois, que perante o "jus in civitate positum" é manifestantemente inconstitucional e contra a legislação complementar, como também contra o direito pretoriano já assentado ao nível de jurisprudência do Supremo Tribunal Federal, tal cobrança.

XI - Quanto à doutrina pátria, salvo manifestações isoladas e que estão ao arrepio da lei e da jurisprudência, basta apontar que HELY LOPES MEIRELLES, demonstrando seu espírito imparcial, científico e nobre, reexaminando toda a matéria, em sua recente obra Finanças Públicas, conclui:

"Somente a conjugação desses dois requisitos especificidad'e e divisibilidade - aliada à compulsoriedade do serviço, pode autorizar a imposição de taxa. Destarte, não é cabível a cobrança de taxa pelo calçamento de via pública ou pela iluminação de logradouro público, que não configuram serviços específicos, nem divisiveis, por serem prestados "uti universi" e não "uti singuli", do mesmo modo que seria ilegal a imposição de taxa relativamente aos transportes urbanos postos à disposição dos usuários, por faltar a esse serviço, específico e divisível, o requisito da compulsoriedade de utilização.

O funcionamento do serviço é condição para que a Administração possa exigir o recolhimento da taxa. Com efeito, determinando a Constituição da República que as taxas são devidas pela utilização dos serviços prestados ao contribuinte ou postos a sua disposição, não basta a criação do serviço e a conseqüente instituição da taxa para obrigar o administrado ao recolhimento do tributo; é preciso que a utilidade esteja em condições de ser usufruida por seus destinatários, ou, em outras palavras, que o serviço fun- 
cione efetivamente. Neste sentido, aliás, já decidiram nossos Tribunais muito antes da inovação trazida pela Emenda Constitucional $18 / 65$ para o direito tributário". "(TJSP RT 200/339; TASP RDA 44/140, 54/70; RT 199/539, 231/593 e 273/608)" (Ed. Rev. Tribunais, S. Paulo, 1979, págs. 15 e 16).

E importante ressaltar que o ilustre autor, dos mais conceituados administrativistas de nosso país, elogiavelmente esclarece pela nota de rodapé 14 à pág. 15:

"14 - Relativamente ao serviço de iluminação pública, já defendemos a tese da legalidade da taxa para seu custeio. Evoluímos para a posição atual por verificarmos que esse serviço não é prestado "uti singuli", mas sim, "uti universi", insuscetível, portanto, de utilização individual e mensurável"

XII - Também o não menos notável jurista e autor José Luiz de Mesquita, no trabalho já citado, compendiando não só a jurisprudência, mas demonstrando a inconstitucionalidade, ilegalidade e arrepio à jurisprudência de opiniões isoladas e superadas, ressalta essa melhor doutrina em harmonia com o direito positivo e as manifestações já sedimentadas pela cúpula do Poder Judiciário. Várias vezes se refere à impossibilidade da cobrança pelo Município da chamada Taxa de Iluminação Pública porque esse serviço público sendo de uso "ut universi" não é referido (vinculado) ao contribuinte, não é específico, não é divisivel como também não é de uso compulsório.

XIII - Bastaria a só constatação de que no caso, o uso comum da iluminação pública nem sequer permitiria de fato nem de direito a cobrança de Taxa, pois é impossível a vinculação aos indetermináveis utentes. Sem a referibilidade, imputação ou vinculação possíveis de cada um ao fato gerador é inócua sua criação. Sujeito passivo do tributo ou da obrigação principal, somente pode ser o contribuinte ou responsável como estatui o art. 121, parágrafo único, I e II do CTN, e de acordo com o art. 128 do mesmo CTN a lei somente pode considerar responsável pelo crédito tributário a pessoa "vinculada ao fato gerador da respectiva obrigação". O STF no Rec. Extr. 77.462MG, publicado na RTJ n. ${ }^{\circ}$ 73, págs. 507 a 513 já deixou esclarecido:

"Atribuição a terceiro da condição de responsável pelo crédito tributário. O art. 128 do CTN, ainda vigente, só a permite se houver vinculação do terceiro ao fato gerador". 
XIV - A atributividade, sujeição ou vinculação ao fato gerador é requisito básico ou necessário para alguém ser contribuinte ou responsável pelo tributo, universalmente.

Em nosso Curso de Direito Tributário, Ed. Saraiva, S. Paulo, 1980, pág. 147, assim expusemos:

"Portanto a qualidade de contribuinte é uma decorrência da realização do fato gerador, ou em outras palavras, a pessoa que realiza o fato previsto na lei como tributável, adquire o status de contribuinte. $\mathrm{Na}$ literatura jurídica alemä, este fenômeno é chamado de Zurechnung, que poderíamos traduzir por responsabilidade pela conta ou quantia, por atributividade do débito, pois Zurechnunasfahigkeit é a responsabilidade pessoal ou imputabilidade (vide Albert Hensel, Steuerrecht cit., pg. 80, sob o título Die Zurechnung, 3. ed., Köoln, Adde: Klaus Tipke, Steuerrecht, 5. ed. Ed. Dr. Otto Schmidt, Colônia, 1978, p. 125. Esta edição já está de acordo com o novo Código Tributário Alemão, em cuja tradução, co-editada por IBDT/ Forense, 1978, veja-se o § 39).

Essa atributividade é assim uma relação ou vínculo que imputa a autoria do fato tributado à pessoa que o realizou e como conseqüência lhe dá a qualidade de contribuinte ou devedor do tributo.

Outra expressão técnica empregada na literatura tributária francesa é l'appartenance fiscale ou na italiana la appartenanza giuridica tributaria ou ainda tedesca stuerliche Zugehörichkeit, que podemos traduzir por atributividade jurídico-tributária, ou ainda sujeição tributária.

$\mathrm{Na}$ impossibilidade de atingir o contribuinte natural, o legislador admite ainda, como sujeito passivo, o

2) Responsável - quando, sem revestir a condição de contribuinte, sua obrigação decorra de disposição expressa de lei.

Observe-se que o responsável é um terceiro em relação ao contribuinte, mas não alheio ao fato gerador. O art. 128 do CTN prevê que seja uma pessoa vinculada ao fato gerador da respectiva obrigação."

XV - Além de não ocorrer nenhum dos pressupostos exigidos para compor a situação definida em lei como necessária e suficiente à ocorrência do fato gerador da obrigação principal (art. 114 do CTN) do tributo taxa, é preciso atentar-se para mais um aspecto relevante da lógica dos tributos na composição de um verdadeiro Sistema Tributário.

$\overline{\mathrm{E}}$ interessante observar que já em 1867, M. Pescatore publicou em Torino a obra Lógica dos Impostos (La Logica delle imposte). Era o início da demonstração de que os 
tributos não deviam se confundir ou se interpenetrarem. Com o desenvolvimento do Direito Tributário se chegou à instituição de Sistema Tributário sob a premissa da capacidade contributiva e para impedir que cada situação venha a ser sobreposta por diferentes e conflitantes tributos. Sistema é uma composição orgânica ou harmônica. Dentro de um sistema tributário não deve ocorrer "bis in idem" econômico ou como a literatura norte-americana refere, "overload" tributário, nem tão pouco uma bitributação ou conflito de competências que seria um "overlap". Este aspecto é da maior relevância não só do ponto de vista econômico ou das relações entre economia e direito, mas sobretudo da harmonia entre os diferentes tributos, dentro de um verdadeiro Sistema Tributário.

Sobre a harmonia interna dos vários tributos dentro de um Sistema, vide a notável obra na Suíça, de HEINZ HALLER, Die Steurngrundlinien Eines Rationalen Systems öffentlicher Abgaben (Os Impostos - Linhas Fundamentais de um Sistema Tributário Racional), 2. ${ }^{\mathrm{a}}$ ed., J. C. Mohr, Tübingen, 1981 e nosso livro Direito Tributário Aplicado e Comparado, ed. Forense, Rio, 1977, vol. II, págs. 100 e segs. É a Teoria das Relações entre os Tributos, isto é, os impostos, taxas e contribuiçôes, que não podem se confundir ou se sobreporem.

Pois bem.

XVI - Precisamente para impedir tais conflitos, sobreposições ou caos tributário é que foi normatizado organicamente um Sistema Tributário Nacional e utilizada a técnica da rígida discriminação constitucional dos impostos, empregada para a especificação destes na distribuição das competências, especificação esta não só nominal dos impostos, mas ainda para as taxas e contribuições, toda a instrumentalidade dos conceitos.

Assim, para os impostos, a Constituição especificou privativa, nominal e pela descrição nuclear dos respectivos fatos geradores, os impostos de competência federal - art. 21 e $\S$ $1 .^{\circ}$ e $\S 5 .^{\circ}$ do art. 18 ; para os estaduais art. 23 e para os municipais art. 24 e, até onde interessa examinar neste trabalho, para as taxas e contribuições os conceitos precisos dos itens I e II do art. 18.

Além disso, no $\S 10^{\circ}$ do art. 18 previu a nossa Lei Fundamental o estabelecimento de normas gerais de direito tributário, as disposições sobre os conflitos de competência nessa matéria e regulação das limitações constitucionais do poder de tributar, por meio de legislação complementar da Constituição. 
Assim sendo, e especificamente para delimitar o poder de taxar e não permitir a instituição de taxas em relação a "situações" já atingidas por impostos, cuja arrecadiação se des. tina à cobertura de serviços públicos gerais ou de uso comum (como o da iluminação pública), estatuiu a Constituição $\mathrm{Fe}$ deral:

Art. $18-$

$\S 20$ - Para cobrança de taxas não se poderá tomar como base de cálculo a que tenha servido para a incídência dos impostos.

XVII - Também o CTN, com a função complementar que a Constituição lhe dá, de regular as limitações constitucionais do poder de tributar, explicitou mais ainda:

Art. 77 - .

Parágrafo único - A taxa não pode ter base de cálculo ou fato gerador idênticos aos que correspondem a imposto,

Ora, a Constituição Federal já outorga somente à União, isto é, privativamente, o imposto sobre o uso, utilização ou consumo da energia elétrica, assim dispondo:

Art. 21 - Compete à União instituir imposto sobre: VIII - consumo . de energia elétrica, imposto que incidirá uma só vez sobre qualquer dessas operações, excluída a incidência de outro tributo sobre elas;

XVIII - A legislação federal também já é completa sobre esta matéria, bastando citar que o Decreto Federal n. ${ }^{\circ}$ $68.419 / 71$, com base na legislação ordinária, dispõe:

Art. $10^{\circ}$ - A energia elétrica entregue ao consumo está sujeita ao imposto único, cobrado pela União, na forma deste Regulamento.

Este é o chamado "imposto único" que exclui não apenas qualquer outro imposto, mas qualquer taxa de consumo, pois como se vê da CF, ela veda a incidência de outro tributo sobre qualquer uso, gasto, utilização ou consumo da energia elétrica. Só e só por este texto constitucional, vê-se que também já é vedado ao Município fazer incidir taxa sobre o consumo ou uso da energia elétrica, quer dentro dos estabelecimentos, das residências e muito menos sobre o povo que use ou consuma, facultativamente, a energia elétrica da iluminação pública. 
XIX - Poder-se-ia dizer que, nos termos da questão suscitada, a chamada taxa de iluminação pública teria como "fato gerador" não o "consumo de energia" mas o "serviço de manutenção da rede elétrica", como denominado no Anteprojeto de Código Tributário Municipal de São Paulo, em elaboração e assim o fato gerador não seria idêntico ao do imposto único?

A nosso ver isto seria apenas um sofisma ou deixar a substância, a natureza das coisas, para se apegar ao abuso das formas. Seria tomar a embalagem ou continente pelo conteúdo.

A iluminação pública não vem pelo ar. $O$ povo não usa ou consome os postes, fios ou lâmpadas, enfim a instalação, mas apenas usufrui a claridade, como de dia, a do sol e pelas vias e logradouros não iluminados, às vezes, ainda, a do plenilúnio e/ou das estrelas que o Bom Deus lhes dá. Os postes, os fios e as lâmpadas são apenas estamentos, insumos ou veículos da iluminação elétrica. Esta, e não aquelas, é o bem de uso, consumo, enfim, a utilidade pública ou comum.

Bastaria, a nosso ver, perguntar se alguém pode usar, utilizar-se, usufruir ou consumir a iluminação pública, sem que esta esteja instalada e mantida em funcionamento.

É evidente que cabe ao Município, entre as suas funções, não só a de executar obras de instalações de iluminação pública indenizáveis por Contribuição de Melhoria, como também a da manutenção das respectivas redes elétricas, para uso comum do povo, cuja manutenção deve ser custeada com a arrecadação dos impostos, porque estes gastos são despesas gerais.

\section{Direito Tributário Comparado}

$\mathrm{XX}$ - Para finalizar, vejamos no exterior o entendimento dos maiores especialistas, não só em obras monográficas sobre as taxas, mas ainda em obras sobre os tributos, para ressaltar as especificidades daquela e demonstrar a convivência harmônica entre impostos, taxas e contribuições, pois cada um é categoria própria, são inconfundíveis e harmonizados dentro dos respectivos Sistemas.

1. Em uma das mais notáveis, e mais completa monografia, com 347 páginas, sob o título preciso de Gebürenrecht und Grundgesetz - Ein Beitrag zum allgemeinen Abgabenrecht (Direito das Taxas e Constituição - uma contribuição ao Direito Financeiro Geral), o Professor Dieter Wilke, como luva confortável ao presente caso, esclarece com estas palavras que traduzimos do original: 


\begin{abstract}
"Distinguindo-se do imposto, a taxa é um tributo cuja exigência depende de uma prestação estatal individualmente imputável (ou atribuível, referida, vinculada).

Pressuposto de uma prestação sujeita à taxa ou de uma situação taxável é ser a mencionada prestação de natureza pública divisível. Em contraposição segundo K. T. von Eheberg, os impostos "se destinam à cobertura dos gastos gerais acarretados pela coletividade, cuja distribuição é impossível pela natureza comunitária destas prestações públicas"

A atribuição ou divisão individualizada de prestações públicas permite uma delimitação, razoavelmente clara, entre prestações que devam ser custeadas pela taxa e aquelas que devam ser exclusivamente financiadas por meio de impostos". (Editora C. H. Beck, München, 1973, pág. 67).
\end{abstract}

2. Como já vimos, enquanto para a obra de instalação da iluminação pública, como melhoramento, é possível cobrar a Contribuição de Melhoria, já pelo uso comum da iluminação pública não é possível cobrar taxa, porque o serviço de sua manutenção é serviço geral e deve ser custeado pelos impostos. Assim já em sua grandiosa obra $A$ Treatise on The Law of Taxation de 1903, o clássico THOMAS M. COOLEY, falando especificamente da iluminação das ruas (lighting streets), já esclarecia com estas palavras que, do original, assim passamos para nosso idioma:

\begin{abstract}
"ILUMINAÇÃO DAS RUAS - Embora o serviço de iluminação das ruas seja custeado pelo imposto, nenhuma razão existe pela qual não possa ser cobrada a Contribuição de Melhoria. Para tal existe em vários Estados legislação de Contribuição de Melhoria".
\end{abstract}

Tendo sido contestada, àquela época, nos EE.UU., a cobrança da Contribuição de Melhoria, sob a alegação de que os contribuintes já pagavam os impostos gerais, cita o Autor, no rodapé $n .^{\circ} 1$ da mesma página 1.178, acórdão que decidiu pela possibilidade de ser indenizado o custo da obra de instalação por meio da Contribuição de Melhoria, baseado em que essa obra pública acarretava a melhoria ou benefício aos respectivos proprietários, nestes termos:

"Os postes, fios e lâmpadas de um sistema de iluminação da rua configuram melhoria do local, cujo custo deve ser lançado a cargo do beneficiário". (3. a Edição Callaghan and Company, Chicago, 1903, vol. II, pág. 1.178). 
Como se vê, a Contribuição de Melhoria é paga pela consideração de a obra tornar iluminada a rua, jamais se falando em taxa (em inglês "fee") para manutenção dessa iluminação, a ser usada em comum e, por isso, daí em diante mantida como despesas gerais, pelos impostos.

3. Outro destacado tributarista, KARSTEN UFFHAUSEN, escrevendo agora sobre $A$ Taxa de Uso (Die Benutzungsgebühr), também ressalta:

"Como a taxa é pagamento de uma prestação estatal específica, ela pressupõe, obrigatoriamente, que esta prestação seja de natureza específica. Isto significa que somente pode ser exigida uma taxa quando é concedido ao cidadão um serviço específico, isto é, uma prestação estatal que exceda às prestações estatais genéricas e mais, que só possa ser exigida uma taxa até esta prestação se revelar como específica, como também ser destinada a uma pessoa determinada" (Die Benutzungsgebühr, KARSTEN UFFHAUSEN, edição do Autor, pág. 56, Göttingen, 1970).

4. O insuperável Mestre dos Mestres, Seligman, no vol. II de seu afamado Ensaio Sobre o Imposto, traçando as diferenças entre este e a taxa de serviços, já ensinava também, que

"Esta é uma retribuição compulsória por um serviço no qual deve estar presente o elemento interesse público, mas a taxa difere do imposto por vários pontos importantes".

Começando por ressaltar que a primeira característica do imposto é a sua qualidade de tributo arrecadado em função da capacidade contributiva e destinado à cobertura das despesas gerais, isto é, para pagar àquelas que, como a despesa de manutenção de iluminação pública, por ser de uso comum do povo não permite ser indenizada pela taxa, posto que, sendo a iluminação pública de uso facultativo e indeterminavelmente de todos, não ser esse serviço atribuível, imputável ou cobrável de ninguém, passa ainda a destacar, com precisão, que:

\footnotetext{
"A base do imposto é a capacidade do contribuinte; a base da taxa é a vantagem especial que usufrui 0 indivíduo.

Se se trata de um imposto, é verdade que esta capacidade pode ser influenciada em certa medida pelas "oportunidades", ou os privilégios ou as vanta-
} 


\begin{abstract}
gens recebidas. Porém, a diferença reside na mensurabilidade. Quando se trata de taxa, a prestação pode ser medida: se estamos diante de um imposto a vantagem não é suscetível de ser diretamente avaliada. Se se trata de taxa, o serviço específico é a verdadeira razão do pagamento; se se trata de um imposto, o serviço particular, se existir, será um simples resultado ocasional da ação do Estado". (Trechos que traduzimos da versão francesa da $8 .^{a}$ edição americana do Essais on Taxation: Essais sur L'Impôt, traduction par Louis Suret, edição M. Giard \& É. Brière, Paris, 1914, vol. II, págs. 136/137).
\end{abstract}

5. Ainda na monografia As Taxas (Die Gebühren), de autoria de dois mestres de Colônia, HANSMEYER e FürsT, no $\S 8$, tratando de $A$ Seleção ou Escolha dos Objetos ou Priestações Taxáveis (Die Wahl des Gebührenobjekts), acentuam:

\footnotetext{
"Primeiro pressuposto para que um objeto possa ser suscetível da cobrança de uma taxa é que o Estado (o Município - Die Gemeinde), ofereça uma prestação (serviço) imputável a um indivíduo ou a um grupo, cobrindo uma necessidade individual dos cidadãos. A palavra necessidade individual indica que esta necessidade é sentida e avaliada pelo indivíduo ou grupo.

Prestações que sejam de interesse exclusivo da coletividade (isto é, comum ou de todos), estão, pois, expressamente excluidas do campo da TAXA". (Die Gebühren - Zur Theorie eines Instrumentariums der Nachfragelenkung bei öfentlichen Leistungen, von Prof. Dr. Karl Heinrich Hansmeyer un Diplom-Volkswirt Dietrich Fürst, Köln, Editora Kohhamer, Stuttgart — Berlin-Köln-Mainz, 1968, pág. 43).
}

XXI - Em conclusão, enquanto dentro da lei e da lógica ou harmonia do Sistema Tributário Nacional entendemos cabível a Contribuição de Melhoria para indenizar os custos da obra pública de iluminação e dos estamentos desta, entendemos que não é constitucional, legal ou juridicamente possível a cobrança de taxa dos munícipes, para custear a manutenção do serviço comum da iluminação pública. $\mathrm{O}$ custo dessa manutenção é despesa geral, a ser custeada com a arrecadação dos impostos. 